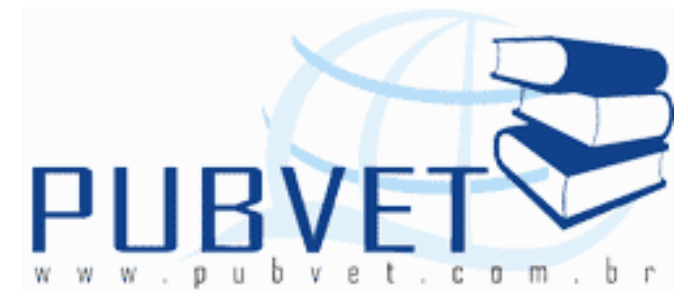

PUBVet, Publicações em Medicina Veterinária e Zootecnia.

\title{
Utilização de batata inglesa na dieta de ruminantes
}

$\overline{\text { Juliana Sávia da Silva }}{ }^{1}$, Ana Luiza da Costa Cruz Borges ${ }^{2}$, Ricardo Reis e Silva ${ }^{2}$, Anna Carolynne Alvim Duque ${ }^{1}$, André Santos de Souza ${ }^{1}$, Alexandre Lima Ferreira $^{1}$, Iran Borges ${ }^{2}$

${ }^{1}$ Doutorando em Zootecnia, Escola de Veterinária da UFMG E-mail: julamim@yahoo.com.br

${ }^{2}$ Prof. Departamento de Zootecnia, Escola de Veterinária da UFMG

\section{Resumo}

O beneficiamento e as indústrias processadoras de batata inglesa (Solanum tuberosum L.) produzem uma grande quantidade de subprodutos que necessitam ser descartados. Objetivou-se revisar as formas de utilização da batata inglesa em dietas de ruminantes. A batata pode ser usada para vacas em lactação e bovinos de corte com a finalidade de se elevar a produção de leite e carne. Os valores nutricionais dos constituintes e dos subprodutos variam conforme a variedade da batata e o tipo de resíduo. O tubérculo pode ser fornecido in natura ou como subprodutos da indústria de processamento na forma de farelos ou silagens.

Palavras-chave: tubérculo, energia, farelo, silagem 
SILVA, J.S. et al. Utilização de batata inglesa na dieta de ruminantes. PUBVET, Londrina, V. 7, N. 7, Ed. 230, Art. 1523, Abril, 2013.

\title{
Use of potato in the diet of ruminants
}

\begin{abstract}
The beneficiation and processing industries of potato (Solanum tuberosum L.) produce a large amount of by-products that need to be discarded. The objective was to review the use of forms of potato in the diet of ruminants. The potato can be used for lactating cows and beef cattle in order to increase the production of milk and meat. The nutritional values of the constituents and byproducts vary according to the variety and type of potato residue. The tuber may be supplied as fresh or industrial processing byproducts in the form of meal or silage.
\end{abstract}

Keywords: tuber, energy, meal, silage

\section{INTRODUÇÃO}

$\mathrm{O}$ beneficiamento $\mathrm{e}$ as indústrias processadoras de batata inglesa (Solanum tuberosum L.) produzem uma grande quantidade de subprodutos que necessitam ser descartados. Esses resíduos podem ser utilizados na alimentação de ruminantes por apresentarem altos teores de amido e por minimizar os custos de produção. Além disso, a possibilidade de uso dos tubérculos impróprios para o consumo humano elimina um problema econômico e ambiental.

Objetivou-se revisar as formas de utilização da batata inglesa em dietas de ruminantes.

\section{REVISÃO BIBLIOGRÁFICA}

A batata (Solanum tuberosum L.) é originária dos Andes peruanos e bolivianos, onde é cultivada há mais de 7.000 anos. Foi introduzida na Europa antes de 1520 e chegou ao Brasil no período da colonização (ABBA, 2012). Atualmente é produzida em 140 países. 
SILVA, J.S. et al. Utilização de batata inglesa na dieta de ruminantes. PUBVET, Londrina, V. 7, N. 7, Ed. 230, Art. 1523, Abril, 2013.

Segundo o Instituto Brasileiro de Geografia e Estatística (IBGE, 2012), a estimativa de produção de batata-inglesa no Brasil para 2012 é de 3.785.257 toneladas. Minas Gerais é o maior produtor nacional de batata-inglesa, com $31,6 \%$ da produção total, seguido por Paraná, com 19,6\%, São Paulo, com $17,8 \%$ e Rio Grande do Sul, com 10,0\%. Esses estados respondem juntos por $79,0 \%$ da produção nacional. Hoje são desperdiçadas de 10 a $15 \%$ da produção total, correspondendo a mais 378 mil toneladas. Sendo $5 \%$ dos descartes devido aos danos provocados por insetos, doenças ou graves perdas mecânicas.

$\mathrm{Na}$ indústria, aproximadamente $35 \%$ da batata produzida são descartadas. Durante este processo há vários tipos de perda, havendo várias formas de processamento para uso na nutrição animal: farelo de batata, batata úmida e torta de filtro de batata. No Brasil a maior fonte disponível constitui-se dos descartes no campo, no processo de lavagem e seleção, ou quando o preço inviabiliza a comercialização (Balsalobre, 1995).

\section{Valor nutricional}

O valor nutricional dos componentes da planta varia conforme a variedade de batata e é semelhante ao da mandioca e da batata-doce (Tabela 1).

Segundo Boyles (2012), todos os subprodutos da batata inglesa são uma excelente fonte de energia para ruminantes. Numa base de $100 \%$ de matéria seca (MS), teriam $81-82 \%$ de nutrientes digestíveis totais (NDT). A maioria dos subprodutos de batata tem pouca gordura, mas resíduos de batatas fritas podem conter até $30 \%$ de gordura na MS. As batatas são praticamente desprovidas de fibra. Na Tabela 2, verifica-se a composição nutricional dos subprodutos da batata. Observa-se que o teor de proteína dos subprodutos está entre 4 e 17,5\%.

O resíduo agrícola da batata, a batata diversa, torna-se uma alternativa viável em função de ser constituída, em média, de $57 \%$ de amido na MS e da grande quantidade produzida anualmente (Rezende, 2005). 
SILVA, J.S. et al. Utilização de batata inglesa na dieta de ruminantes. PUBVET, Londrina, V. 7, N. 7, Ed. 230, Art. 1523, Abril, 2013.

A batata possui um conjunto de toxinas naturalmente presentes em todas as partes da planta. A solanina, a qual é uma das principais toxinas encontradas nas batatas, é inibidora de colinesterase. No entanto, a batata só se torna tóxica quando fica com a cor verde, sendo que as toxinas alcaloides concentram-se nessa parte (Simões, 2008).

Tabela 1. Composição média de $100 \mathrm{~g}$ de matéria fresca de tubérculo de batata e das raízes de mandioca e batata doce

\begin{tabular}{l|c|c|c}
\hline \multirow{2}{*}{ Componente } & \multicolumn{3}{|c}{ Quantidade } \\
\cline { 2 - 4 } & Batata & Mandioca & 70,0 \\
\hline Umidade (\%) & 78,0 & 63,0 & 26,1 \\
\hline Carboidratos totais (g) & 18,5 & 32,4 & 1,5 \\
\hline Proteína (g) & 2,1 & 1,0 & 0,3 \\
\hline Lipídios (g) & 0,1 & 0,3 & 32,0 \\
\hline Cálcio (mg) & 9,0 & 39,0 & 39,0 \\
\hline Fósforo (mg) & 50,0 & 41,0 & 0,7 \\
\hline Ferro (mg) & 0,8 & 1,1 & 3,9 \\
\hline Fibras digestíveis (g) & 2,1 & 4,4 & \\
\hline
\end{tabular}

Fonte: Woolfe (1992) citado por Veiga et al. (2009) 
SILVA, J.S. et al. Utilização de batata inglesa na dieta de ruminantes. PUBVET, Londrina, V. 7, N. 7, Ed. 230, Art. 1523, Abril, 2013.

Tabela 2 - Valor nutricional dos subprodutos da batata na base da MS

\begin{tabular}{|c|c|c|c|c|c|c|c|}
\hline Itens & $\begin{array}{l}\text { Torta } \\
\text { de } \\
\text { filtro }\end{array}$ & $\begin{array}{l}\text { Farelo } \\
\text { de } \\
\text { batata }\end{array}$ & Tubérculo & $\begin{array}{l}\text { Tubérculo } \\
\text { cozido }\end{array}$ & $\begin{array}{l}\text { Folha } \\
\text { de } \\
\text { batata }\end{array}$ & $\begin{array}{l}\text { Farelo } \\
\text { de } \\
\text { folhas }\end{array}$ & $\begin{array}{l}\text { Casca } \\
\text { de } \\
\text { batata }\end{array}$ \\
\hline MS\% & 14,1 & 86,13 & 24,1 & 29 & 18,04 & 91,2 & 21,2 \\
\hline PB & 4,8 & 12,36 & 12,1 & 6 & 8,29 & 17,5 & 9,9 \\
\hline FDA & & 6,22 & & & & & \\
\hline FDN & & 13,21 & & & & & \\
\hline AM & & 57,02 & & & & & \\
\hline FB & 2,3 & & 3,9 & 2,3 & 26,28 & 39,1 & 3,3 \\
\hline EE & 7,7 & 3,80 & 0,9 & 1,3 & 3,34 & 6,4 & 0,5 \\
\hline$C Z$ & 3,1 & 3,56 & & & & & \\
\hline $\mathrm{Ca}$ & 0,135 & 0,07 & & & & & \\
\hline$P$ & 0,193 & 0,18 & 0,1 & 0,106 & 0,06 & 1,39 & \\
\hline K & 0,235 & 0,94 & 0,2 & 0,157 & 0,08 & 0,14 & \\
\hline NDT\% & & & 80 & & 55,08 & & \\
\hline
\end{tabular}

PB: proteína bruta; FDA: fibra em detergente ácido; FDN: fibra em detergente neutro; AM: amido; FB: fibra bruta; EE: extrato etéreo; CZ: cinzas; Ca: cálcio; $\mathrm{P}$ : fósforo; $\mathrm{K}$ : potássio.

Fonte: Adaptado de Balsalobre, 1995 e Valadares et al., 2012.

\section{Utilização na alimentação de ruminantes}

Batata diversa é o nome atribuído ao tubérculo impróprio para o consumo humano, por não alcançar padrões de comercialização tanto em tamanho quanto em qualidade. Além da qualidade nutricional, a batata diversa tem baixo custo, por ser considerada como resíduo agrícola (Rezende, 2005).

A batata diversa in natura pode ser usada para vacas em lactação e bovinos de corte com a finalidade de se elevar a produção de leite e carne. As maneiras para se fornecerem batatas in natura aos animais são: espalhá-las no chão (Boyles, 2012); ensilá-las em camadas, em um silo horizontal, com 
SILVA, J.S. et al. Utilização de batata inglesa na dieta de ruminantes. PUBVET, Londrina, V. 7, N. 7, Ed. 230, Art. 1523, Abril, 2013.

feno (Snowdon, 2012); ou como propôs Rezende (2005) picá-las ou triturá-las antes de ser fornecida para reduzir a incidência de asfixia. O tubérculo inteiro pode escapar da mastigação do animal, alojar-se no esôfago, obstruindo-o fisicamente, causando timpanismo ruminal secundário.

A batata in natura apresenta alto percentual de deterioração em ambientes quentes, tornando difícil a manutenção das suas qualidades organolépticas por períodos superiores a uma semana, o que dificulta o seu armazenamento e permite classificá-la como perecível. Além disso, devido ao alto conteúdo de água existem limites econômicos sobre a distância que a batata pode ser transportada. Rezende (2005) sugeriu que a melhor maneira de utilizá-la na alimentação animal deveria ser alguma forma de conservação, que pode ser a desidratação para fazer o farelo, podendo assim ser armazenado por maior tempo, ou mesmo a ensilagem com algum material que cause elevação do teor de MS.

Alguns comerciantes de carne acreditavam que animais alimentados com batata produziam carnes mais aguadas e com coloração inferior. Nelson (2000) determinou os efeitos de dietas com cevada ou milho, ambas contendo 0, 10 ou $20 \%$ de subprodutos de batata com base no desempenho de bovinos em confinamento e características de carcaça. Os subprodutos de batata (pedaços de batata não cozidos e ensilados) continham 11,6\% PB, 55,9\% de amido, $21 \%$ de FDN e $17,4 \%$ de FDA na base da MS. Os Novilhos foram alimentados com dietas contendo $83 \%$ de concentrado, $7 \%$ de alfafa e $10 \%$ de suplemento (ureia, minerais e vitaminas) por 130 dias. O consumo e ganho de peso foram maiores para a dieta de milho com $10 \%$ de batata. As dietas provocaram o mínimo de efeito na aparência e composição da carne e nas características da carcaça. E segundo o autor, a percepção de que animais alimentados com batatas podem resultar em carne inferior também não foi verificada.

As cascas de batata são um alimento atrativo na dieta de animais por causa de sua disponibilidade, sua alta concentração de energia e seu baixo custo. Monteils et al. (2002) realizaram um estudo tratando apenas dos aspectos ruminais, comparando o farelo de trigo (64,5\% de amido, $12,6 \%$ de 
SILVA, J.S. et al. Utilização de batata inglesa na dieta de ruminantes. PUBVET, Londrina, V. 7, N. 7, Ed. 230, Art. 1523, Abril, 2013.

PB e $15,7 \%$ de FDN na MS) e a casca de batata (69\% de amido, $6,8 \%$ de PB e $10,7 \%$ de FDN na MS), com ênfase sobre a fração amido e a mudança de cinética de fermentação, em vacas leiteiras. Esses alimentos foram estudados com dois tipos de ração total (TMR), sendo a primeira à base de silagem de capim e a segunda à base de silagem de milho. O farelo de trigo ou casca de batata representava 35 a $40 \%$ de MS total. As cascas de batata foram resíduos da indústria de descamação de batata frita, armazenadas na forma de silagem $(\mathrm{pH} 4)$. Os consumos de MS, amido, nitrogênio e FDN por vacas foram semelhantes para os dois concentrados em ambas as dietas. O amido do farelo de trigo foi mais rapidamente $(34 \% / \mathrm{h})$ degradado por micro-organismos do rúmen do que o amido da casca de batata $(5 \% / \mathrm{h})$. O desaparecimento da fração amido do farelo de trigo ou casca de batata não estava ligado ao tipo de volumoso na dieta. Os autores concluíram que as diferenças do perfil de fermentação foram tão reduzidas em dietas à base de silagem de milho que o trigo pôde ser substituído por batata sem qualquer efeito sobre a digestão e nenhum risco de acidose ruminal.

Radunz et al. (2003) avaliaram os efeitos da inclusão (0, 10, 20, 30 e $40 \%$ ) de resíduos de batata em dietas de confinamento no desempenho e na qualidade da carne de bovinos de corte em fase acabamento. A dieta continha $45 \%$ de milho, $45 \%$ de alfafa, $5 \%$ de melaço desaçucarado e $5 \%$ de suplemento (mineral, vitaminas e ureia) na MS. Os resíduos utilizados foram obtidos da indústria de produtos congelados de batata (13\% MS, 10,1 de PB\%, $53,1 \%$ de amido e $37,5 \%$ de FDN na MS) e continha pedaços de batata e outros materiais solúveis produzidos durante o processamento. A ingestão de matéria seca (IMS) e os ganhos de peso diários foram menores com o aumento da inclusão do resíduo de batata. Os autores concluíram que a adição de $10 \%$ de resíduos de batata na dieta teve pouco efeito sobre o consumo, espessura de gordura e acabamento de bovinos de corte.

Pen et al. (2006) determinaram o efeito da inclusão crescente $(0,19 \mathrm{e}$ $27 \%$ ) de silagem de derivados de batata sobre a fermentação ruminal, produção de metano e utilização de nitrogênio. Determinaram também a taxa 
SILVA, J.S. et al. Utilização de batata inglesa na dieta de ruminantes. PUBVET, Londrina, V. 7, N. 7, Ed. 230, Art. 1523, Abril, 2013.

de substituição ótima de silagem à base de subprodutos de batata (SPB) nos concentrados em dietas de engorda de novilhos da raça Holandês. A silagem continha $41 \%$ de $M S, 14,4 \%$ de PB e $23,1 \%$ de FDA na MS. A inclusão aumentou o consumo, a digestibilidade da FDA e não afetou as características fermentação rumenal. Os dados sugerem que a substituição de silagem à base de SPB para os concentrados até $27 \%$ da MS da dieta não aumentou significativamente a produção de metano e melhorou a retenção de nitrogênio.

Rezende (2005) estimou a degradabilidade in situ das silagens de capim napier (Pennisetum purpureum) produzidas com diferentes níveis do farelo de batata diversa $(0 \%, 5 \%, 10 \%, 15 \%$ e $20 \%)$. A batata in natura foi fatiada, seca ao sol até atingir teor de umidade entre 10 e $15 \%$. No ensaio de degradabilidade ruminal in situ utilizou três vacas Jersey adaptadas por 15dias a dieta basal contendo capim ( $60 \%$ da MS) e concentrado ( $30 \%$ de farelo de batata, $37 \%$ de milho, $27 \%$ de farelo de soja, $2 \%$ de ureia, $4 \%$ de suplemento mineral). O estudo mostrou que as adições de $15 \%$ e $20 \%$ de farelo de batata diversa à silagem de capim proporcionaram melhores resultados, caracterizando uma boa silagem, com maiores valores de degradabilidade ruminal in situ da MS, PB e FDN.

Nkosi e Meeske (2010) estudaram o efeito da ensilagem de coprodutos de batata, com ou sem inoculantes bacterianos (Lactobacillus buchneri) em comparação à silagem de milho em 24 cordeiros Dorper, na África do Sul. Esse coproduto da batata, obtido após a produção de petisco, foi composto por uma mistura de casca de batata, amido de milho e óleo de milho. Os ingredientes da TMR foram farelo de milho, óleo de soja, melaço e utilizaram feno somente na dieta com batata. Os autores concluíram que o inoculante foi eficaz na produção de uma boa silagem de batata, o que foi evidenciado pela melhor fermentação e estabilidade anaeróbica, crescimento dos cordeiros e digestibilidade da silagem com batata. O desempenho animal foi melhor quando a silagem de batata foi bem preservada substituindo a silagem de milho na alimentação de ruminantes. 
SILVA, J.S. et al. Utilização de batata inglesa na dieta de ruminantes. PUBVET, Londrina, V. 7, N. 7, Ed. 230, Art. 1523, Abril, 2013.

Tavares et al. (2011) avaliaram a produção e a composição do leite em 12 vacas lactantes ( $25 \mathrm{~kg}$ de leite/dia) alimentadas com silagens contendo batata. Foram quatro tratamentos (silagens): silagens de milho (SM); capim-elefante (SC); capim-elefante com 7\% de batata (SC7\%); e capim-elefante com 14\% de batata (SC14\%). O farelo foi constituído de $85,2 \%$ de MS, $12,64 \%$ de PB\%MS e 58,6\% de amido na MS. A dieta continha polpa cítrica, milho, caroço de algodão, farelo de soja, sal, ureia, premix vitamínico e mineral. Foi necessária a correção do déficit proteico da ração, sendo as diferenças corrigidas com ureia. A adição de resíduo de batata na ensilagem de capim elefante melhorou o consumo (IMS: SC $=17,39, \mathrm{SC} 7 \%=18,23, \mathrm{SC} 14 \%=$ $19,29 \mathrm{~kg} / \mathrm{dia}$ ). A silagem de milho foi superior às demais, pois promoveu maior produção de leite, em $\mathrm{kg}$ de proteína, $\mathrm{kg}$ de extrato seco desengordurado (ESD) e kg de lactose. Não houve diferença entre as silagens para os teores de gordura, proteína, sólidos totais, ESD, lactose e $\mathrm{N}$-ureico no leite $(\mathrm{mg} / \mathrm{dL})$. A SC14\% proporcionou produção de leite $(24,58 \mathrm{~kg} /$ dia $)$ próxima, porém inferior, à obtida com a oferta da SM $(25,19 \mathrm{~kg} / \mathrm{dia})$, com uma diferença de 0,61 kg/dia. A composição do leite observada com a SC14\% foi semelhante à obtida com SM e superior às demais.

A utilização de subprodutos da batata na alimentação dos animais pode eliminar um problema de poluição substancial para a indústria e proporcionar um alimento que possa ser benéfico à produção de ruminantes (Pen et al., 2006), sendo que, se não for utilizado, apresenta um grande custo de tratamento dos resíduos (Nkosi e Meeske, 2010).

Os fatores como o custo de aquisição, transporte, armazenamento, manipulação e fornecimento devem ser levados em consideração quando se contempla o uso de batatas em uma ração, semelhantes aqueles para qualquer subproduto úmido. Radunz et al. (2003) sugerem que a inclusão de resíduos de batata em dietas de terminação pode ser determinada pelo custo em relação a outros componentes da dieta. O preço pago deve permitir que as despesas adicionais previstas para transportar, armazenar e alimentar compense o custo total de se utilizarem batatas na alimentação animal. 
SILVA, J.S. et al. Utilização de batata inglesa na dieta de ruminantes. PUBVET, Londrina, V. 7, N. 7, Ed. 230, Art. 1523, Abril, 2013.

\section{CONSIDERAÇÕES FINAIS}

A batata inglesa é caracterizada por ser rica em água, baixos teores de fibra e proteína. Os valores nutricionais dos constituintes e dos subprodutos variam conforme a variedade da batata e o tipo de resíduo. O tubérculo é um alimento energético que pode ser incluído nas dietas de ruminantes com resultados satisfatórios, quando devidamente utilizado. A batata pode ser fornecida in natura ou como subprodutos da indústria de processamento na forma de farelos ou silagens.

\section{REFERÊNCIAS BIBLIOGRÁFICAS}

ASSOCIAÇÃO BRASILEIRA DA BATATA - ABBA. História da batata. Disponível em: <http://www.abbabatatabrasileira.com.br/2008/abatata.asp?id BAT=2>. Acessado em: 10 set. 2012.

BALSALOBRE, M. A. A. Batata, beterraba, cenoura e nabo. In: SIMPÓSIO SOBRE NUTRIÇÃO DE BOVINOS, 6., 1995, Piracicaba. Anais... Piracicaba: 1995. p. 99-121.

BOYLES, S. Feeding potato processing wastes and culls to cattle. Ohio State University Extension Beef Publications, 2012 Disponível em: <http://beef.osu.edu/library/potato.html>. Acessado em 26 set. 2012.

INSTITUTO BRASILEIRO DE GEOGRAFIA E ESTATÍSTICA - IBGE. Levantamento Sistemático da Produção Agrícola. Disponível em: <http://www.ibge.gov.br/home/presidencia/noticias/noticia visualiza.php?id noticia=2146\&id pagina $=1>$. Acessado em: 10 set. 2012.

MONTEILS, V; JURJANZ, S.; COLIN-SCHOELLEN, O. et al. Kinetics of ruminal degradation of wheat and potato starches in total mixed rations. J Anim Sci., v.80(1), p. 235-241, 2002.

NELSON, M.L. Utilization and application of wet potato processing coproducts for finishing cattle. J Anim Sci., v.88, p.133-142, 2010.

NKOSI, B.D.; MEESKE R. Effects of ensiling totally mixed potato hash ration with or without a heterofermentative bacterial inoculant on silage fermentation, aerobic stability, growth performance and digestibility in lambs. Anim. Feed Sci. Technol., v.161, p.38-48, 2010.

PEN, B.; IWAMA, T.; OOI, M. et al. Effect of Potato By-products Based Silage on Rumen Fermentation, Methane Production and Nitrogen Utilization in Holstein Steers. Asian-Aust. J. Anim. Sci., v19(9), p.1283-1290, 2006.

RADUNZ, E.; LARDY, G P.; BAUER, M.L. et al. Influence of steam-peeled potato-processing waste inclusion level in beef finishing diets: Effects on digestion, feedlot performance, and meat quality. J. Anim. Sci., v.81, p.2675-2685, 2003. 
REZENDE, V.M. Degradabilidade ruminal das silagens de capim-napier produzidas com diferentes níveis de farelo de "batata diversa". 2005. 52f. Dissertação (Mestrado em Zootecnia) - Zootecnia, Universidade Federal de Lavras, Lavras.

SIMÕES, J. Envenenamento por glicoalcalóides da batata (solanum tuberosum) em bovinos. Disponível em: < http://veterinaria.com.pt/media//DIR 27001/VCP1-1-e17.pdf > Acessado em: 10 set. 2012.

SNOWDON, M. FEEDING POTATOES TO CATTLE. Department of Agriculture, Aquaculture and Fisheries. Disponível em: < http://www.gnb.ca/0170/01700002-e.asp>. Acessado em: 10 set. 2012.

TAVARES, V.B.; PINTO, J.C.; BARCELOS, A.F. et al. Efeitos da adição de batata na silagem de capim-elefante sobre o consumo e a produção em vacas leiteiras. R. Bras. Zootec., v.40, n.12, p.2706-2712, 2011.

VALADARES FILHO, S.C.; MACHADO, P.A.S.; CHIZZOTTI, M.L. et al. [2012]. Tabelas Brasileiras de Composição de Alimentos para Bovinos. CQBAL 3.0. Disponível em: <http://cqbal.agropecuaria.ws/webcqbal/index.php>. Acessado em: 10 set. 2012.

VEIGA, I.R.F.M.; GONÇALVES, L.C.; LOBATO, F.C.L. et al. Batata-doce na alimentação de gado de leite. In: GONÇALVES, L.C.; BORGES, I.; FERREIRA, P.D.S. Alimentos para gado de leite Belo Horizonte: FEPMVZ, 2009. 347 p. 